\title{
Comparative analysis of LSG versus LRYGBP bariatric surgery in management of morbid obesity and type 2 diabetes mellitus in terms of percentage weight loss and T2DM resolution
}

\author{
Rajesh Sharma $^{1 *}$, Manoj Kela ${ }^{1}$, Yashasvi Khare ${ }^{1}$, Arun Mishra ${ }^{1}$, Mohit Bhandari ${ }^{2}$
}

${ }^{1}$ Department of Surgery, Sri Aurobindo Medical College \& PG Institute, Indore, MP, India
${ }^{2}$ Mohak Hightech Laparoscopic \& Robotic Bariatric Surgery Centre, SAMC \& PGI, Indore, M.P., India

Received: 15 September 2015

Revised: 16 September 2015

Accepted: 07 October 2015

*Correspondence:
Dr. Rajesh Sharma,
E-mail: rajeshalp@yahoo.co.in

Copyright: () the author(s), publisher and licensee Medip Academy. This is an open-access article distributed under the terms of the Creative Commons Attribution Non-Commercial License, which permits unrestricted non-commercial use, distribution, and reproduction in any medium, provided the original work is properly cited.

\begin{abstract}
Background: Obesity is a major health problem worldwide and in India also \& is a major risk factor associated with significant morbidity and mortality due to comorbid conditions. Surgery is the only effective modality for significant and sustained weight loss \& in resolution of associated diabetes, hypertension, sleep apnea and osteoarthritis. Laparoscopic Bariatric surgery is a unique field, this proven surgical approach provide marked improvement in quality of life with quick recovery.

Methods: Retrospective data analysis of 145 laparoscopic bariatrics surgery 123 LSG \& 22 RYGBP done in patients of morbid obesity alone or with T2DM , HT was analyzed in the study Over a period of three years with mean follow up period of 1-2 years. Patients were evaluated in terms of resolution of percentage weight loss \& T2DM.

Results: In Present study 145 cases of bariatric surgery (mainly SG \& RYGB) were included. Significant weight control of around 40-60 kgs was observed. BMI reduction shift from $29-77$ to $21.1-46.6 \mathrm{~kg} / \mathrm{m} 2$ was recorded. In all diabetes pt, post op reduction in HbA1c $<6$ ( $<6$ normal value) $40 \%$ pt \& near normal range in $35 \%$ proves significant resolution in status of T2DM. Finally LSG \& RYGBP showed almost similar result in \% weight reduction \& glycemic control.

Conclusions: Thus I conclude bariatric LSG / LRYGBP are a definite choice for patient of only morbid obesity \& morbid Obesity with T2DM \& give adequate resolution of problem \& adds to quality of life of patient with cosmetic $\&$ therapeutic benefits
\end{abstract}

Keywords: Morbid, Obesity, T2DM, Bariatric surgery

\section{INTRODUCTION}

Obesity is a major health problem worldwide and has reached an epidemic in the Western society and in India also \& is a major risk factor due to associated comorbidities with significant morbidity and mortality.. It has been shown in longitudinal studies that non-surgical treatment of morbid obesity does not lead to any meaningful weight loss. $90-95 \%$ of people who lose weight regain all or most of their lost weight thus; surgery is the only effective modality for significant and sustained weight loss \& also helps in resolution of associated comorbidities like diabetes, hypertension, sleep apnea and osteoarthritis. Laparoscopic bariatric surgery is a unique field, This proven surgical approach provide improvement in quality of life and the quick recovery Weight loss operations can be divided into restrictive procedures and malabsorptive procedures. Malabsorptive procedures reduce the absorption of calories, proteins and other nutrients. In contrast, restrictive operations decrease food intake and promote a feeling of early fullness (satiety) after meals. Some 
operations are a combination of both: Staged Procedures v/s single procedure Staged Procedures. This approach involves performing a less invasive procedure that reduces weight to a safer level (which in itself is not effective enough on its own) and improves overall medical condition first; then a more complex, definitive procedure is performed once the operative risks of the patient decrease significantly due to the initial weight loss. These less invasive steps have included the laparoscopic "sleeve gastrectomy" the gastric balloon and the adjustable band as an interim step before. Laparoscopic RYGBP or DS or Biliopancreatic Diversion is performed in selected patients less invasive procedures adequately control problem.

\section{Aim and objectives}

Aim and objectives of the study was:

1. Comparative analysis of LSG v/s L RYGBP Bariatric surgery in management of morbid obesity \& T2DM in terms of resolution of $\%$ weight loss \& T2DM.

2. Age \& Sex Incidence \& pattern of obesity in our series.

3. Incidence of co morbid conditions \& its relation with type of obesity.

4. Selection of operative procedure in obese patient/ in comorbid conditions.

5. Comparison of result in reference to comorbid condition and weight reduction.

6. Comparison of result of our study with standard statistic available.

\section{METHODS}

Retrospective data analysis of 145 patient of bariatric surgery 123 of LSG \&, 22 LRYGBP performed for morbid obesity $\&$ associated comorbidities was done over a period of three years, the mean follow up period of 1-2 years. Patients were evaluated in terms of resolution of percentage weight loss \& DM type 2 (T2DM).

\section{Inclusion criteria}

1. Morbid obese with BMI:- 28-80

2. Morbid obesity with T2DM

\section{Exclusion criteria}

1. Type 1 Diabetes mellitus

2. $\mathrm{BMI}<28 \mathrm{~kg} / \mathrm{m}^{2}$

3. Bleeding disorder

4. Multiple previous abdominal surgeries

5. Hiatus hernia

6. Gastric ulcer/lesion

7. Stroke with active anticoagulant treatment

8. Age $>75$ years

\section{Operative procedure}

During the sleeve gastrectomy, about 75 percent of the stomach is removed leaving a narrow gastric tube or "sleeve". No intestines are removed or bypassed during the sleeve gastrectomy. 75 percent of patients will have significant improvement or resolution of major obesityrelated co-morbidities such as diabetes, hypertension, sleep apnea and hyperlipidaemia following sleeve gastrectomy. However, as these procedures are potentially much safer than other operations, they may have a significant role in the future.

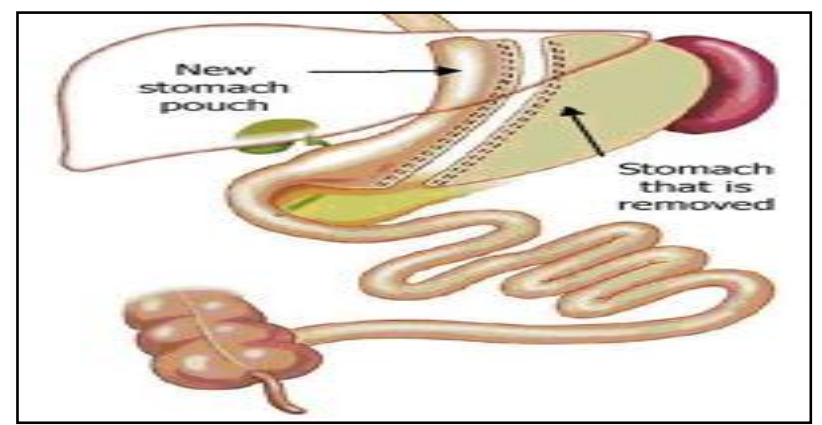

Figure 1: Sleeve gastrectomy.

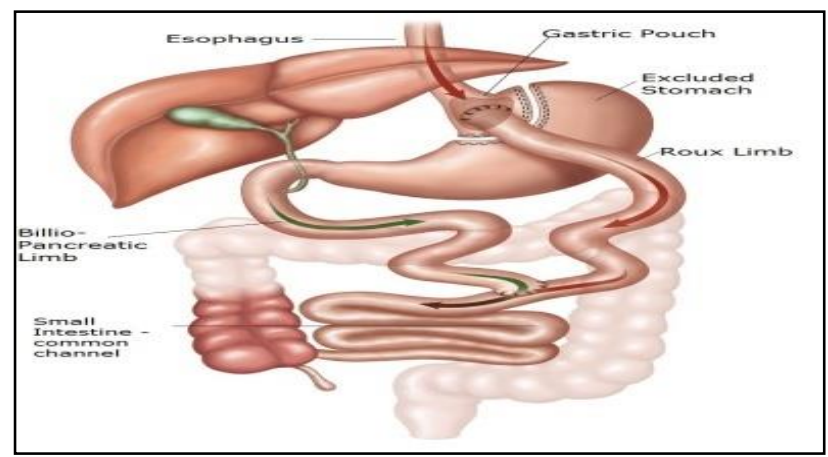

Figure 2: Roux-En-Y gastric bypass (RYGBP).

\section{Gastric bypass}

Dr. Mason and Ito initially developed this procedure in the 1960s. Over several decades, the gastric bypass has been modified into its current form, using a Roux-en-Y limb of intestine (RYGBP). The RYGBP is the most commonly performed operation for weight loss initially the operation was performed as a loop bypass with a much larger stomach. Because of bile reflux that occurred with the loop configuration, the operation is now performed as a "Roux-en-Y" with a limb of intestine connected to a very small stomach pouch which prevents the bile from entering the upper part of the stomach and esophagus. The remaining stomach and first segment of small intestine are bypassed. The RYGBP has been proven in numerous studies to result in durable weight loss and an improvement in weight-related medical illnesses. Half of the weight loss often occurs during the first six months after surgery; weight loss usually peaks 
at 18-24 months. The obesity-related comorbidities that may be improved or cured with the RYGBP include diabetes mellitus of the adult onset type (so-called insulin resistant), hypertension, high cholesterol, arthritis, RYGBP has resulted in marked improvements in quality of life.

\section{RESULTS}

In our study we took $145 \mathrm{pt}$ of obesity operated during may 2011- april 2012 followed them for a period of 1-2 year. Following results noted.

\section{Age variation \& Sex ratio}

Age variation \& sex ratio of pt. was from 17-69 years with maximum number between 41-60(table no.1) \& male were $69(48 \%)$ and female were 76 (52\%) (Figure 2).

Table 1: Age variation \& sex ratio of patients.

\begin{tabular}{|lll|l|}
\hline Group & Age & Number & $\%$ \\
\hline 1 & $<20$ & 5 & 3 \\
\hline 2 & $21-30$ & 25 & 17 \\
\hline 3 & $31-40$ & 27 & 19 \\
\hline 4 & $41-50$ & 43 & 30 \\
\hline 5 & $51-60$ & 35 & 24 \\
\hline 6 & $61-70$ & 10 & 7 \\
\hline & Total & 145 & 100 \\
\hline
\end{tabular}

\begin{tabular}{|c|c|c|}
\hline \multicolumn{3}{|c|}{ Series 1} \\
\hline 69 & 76 & \\
\hline $\begin{array}{l}\text { male } \\
\text { group1 }\end{array}$ & female & total \\
\hline
\end{tabular}

Figure 2: Male female ratio.

\section{Percentage distribution of obesity}

MO-38\% $2>\mathrm{MO} \& \mathrm{DM}-33 \%, 3>\mathrm{MO} \& \mathrm{HTN}-15 \%$ $>\mathrm{MO} \&$ other co morbidities-14\% (Figure 3 ).

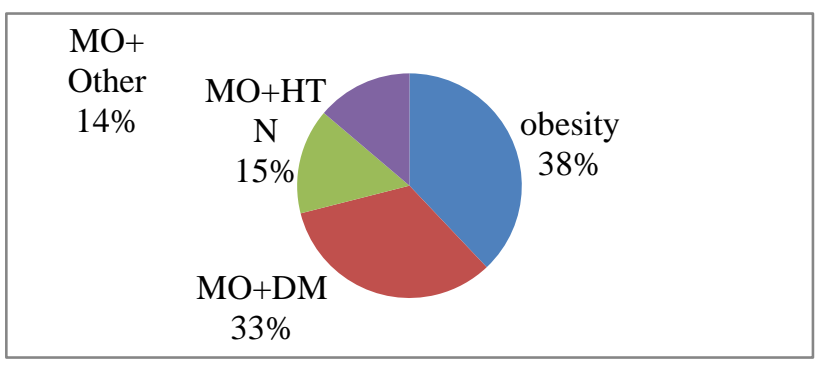

Figure 3: Percentage distribution of obesity.

\section{Weight reduction}

Weight reduction shift from range $92-210 \mathrm{~kg}$ to $55-140$ $\mathrm{kg}$. Average weight reduction in majority was approx. 45 kg. maximum weight range was in between 61-80 Almost equal result in both type of surgeries.

Weight distribution curve with maximum number of patients ranges between $100-140 \mathrm{~kg}$.

Post-operative weight reduction with maximum range in between $61-80 \mathrm{~kg}$.

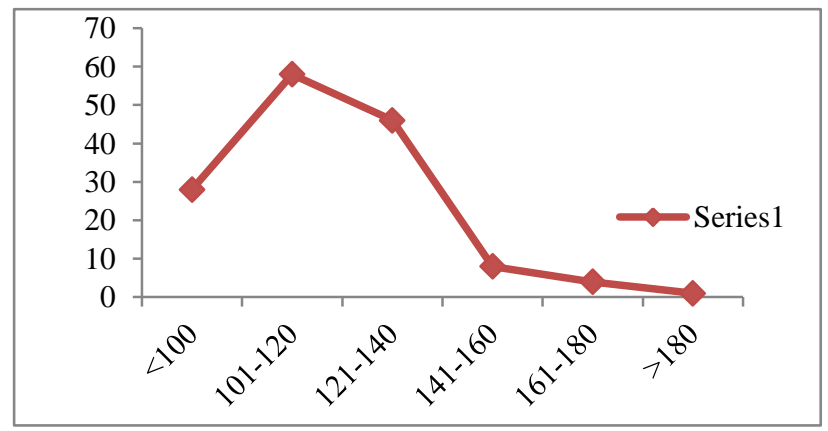

Figure 4: Pre-operative weight reduction.

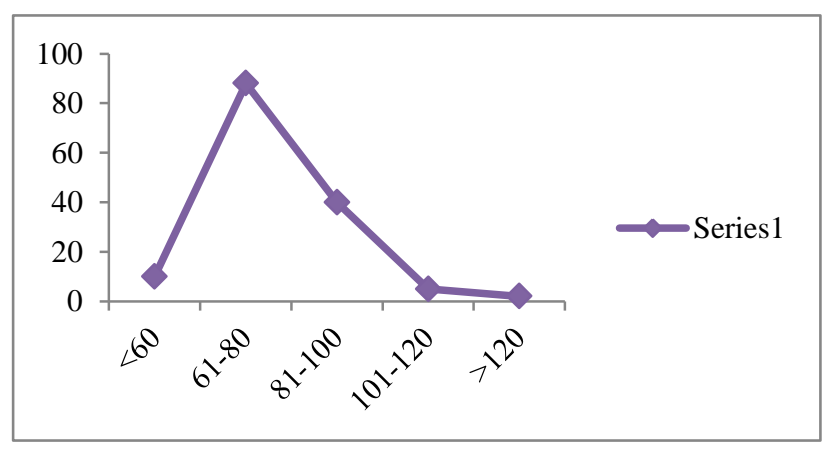

Figure 5: Post-operative weight reduction.

\section{BMI reduction shift}

BMI reduction shift from 29-77 to $21.1-46.6 \mathrm{~kg} / \mathrm{m} 2$. BMI maximum range was reduced to $26-35$.

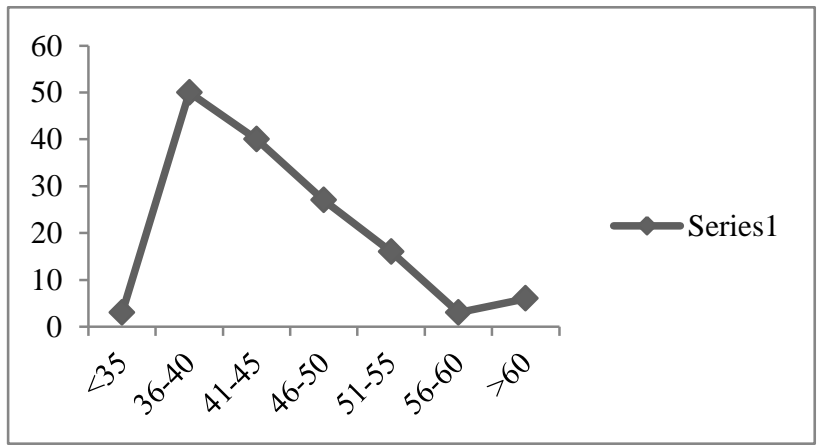

Figure 6: Pre-operative BMI. 


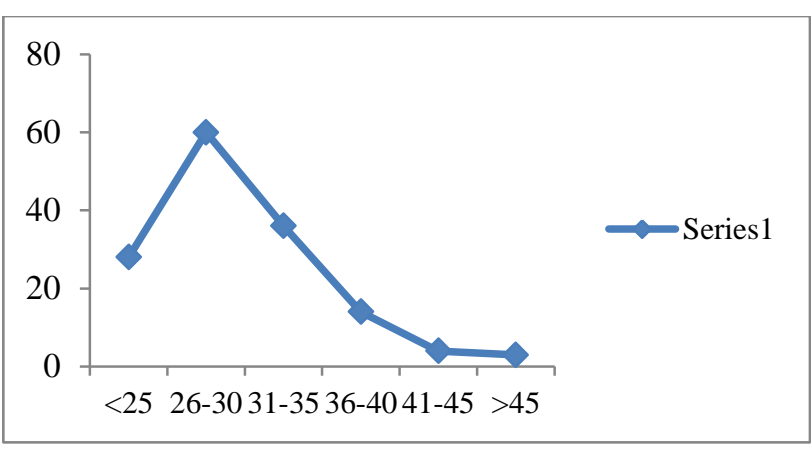

Figure 7: Post-operative BMI.

In diabetic patients, post-operative reduction in hba1c $(<6$ normal value). $40 \%$ were $<6 \& 35 \%$ patients were near normal range (6.1-6.5).

\section{Statistical analysis}

In group $1 \&$ group 2 the chi sq value (22.8) is highly sensitive (HS) as the calculated value is more than the tabulated value with control of diabetes in both groups.

Here also it is found that the chi sq value calculated is found to be more than the tabulated chi sq value at $1 \mathrm{DOF}$ showing that there is highly significant association between the pre-operative \& post-operative weight.

Here in all group the calculated chi sq value is found to be more than tabulated value. Showing that there is highly significant difference in the pre op \& post op BMI after surgery.

\section{DISCUSSION}

In our study of 145 patients we found out that there is definitive weight loss with mean weight loss of around of $40-60 \mathrm{~kg}$ with weight reduction shift from range 92-210 $\mathrm{kg}$ to $55-140 \mathrm{~kg} \&$ BMI reduction shift from 29-77 to 21.1 to 46.6 . Other study done which also suggest weight loss \& BMI reduction are as follows. ${ }^{3-18}$ In all diabetes pt, post-operative reduction in HbA1c ( $<6$ normal value).In $40 \%$ patients were $<6 \& 35 \%$ patients were near normal range (6.1-6.5). There is good glycemic control after bariatric surgery. Other studies which also has glycemic control are as follows. . $2,4,6,8-10,12,14,16-19,21,22^{\text {Type of }}$ surgery in DM in $65 \%$ SG was done \& in $35 \%$. RYGB was done with similar result in glycemic control in both surgeries. Other studies which also has similar results were as follows. ${ }^{16,17,20}$

Type of surgery in DM in 65\% SG was done \& in $35 \%$. RYGB was done with almost similar result in glycemic control in both surgeries.

Table 2: Resolution of T2DM.

\begin{tabular}{|lll|}
\hline HbA1c & No & $\%$ \\
\hline$<6$ & 19 & 40 \\
\hline $6.1-6.5$ & 17 & 35 \\
\hline $6.6-7$ & 10 & 21 \\
\hline$>7$ & 2 & 4 \\
\hline Total & 48 & 100 \\
\hline
\end{tabular}

Table 3: Type of surgery among non-diabetic \& diabetics.

\begin{tabular}{|llllllll|}
\hline & Type of surgery & Non diabetics & Diabetics & P value & DOF (control of diabetes) & Chi sq value \\
\hline Group 1 & SG & 92 & 31 & 0.000 & 1 & 22.8 (HS) \\
\hline Group 2 & GBP & 5 & 17 & 0.000 & 1 & $22.8(\mathrm{HS})$ \\
\hline
\end{tabular}

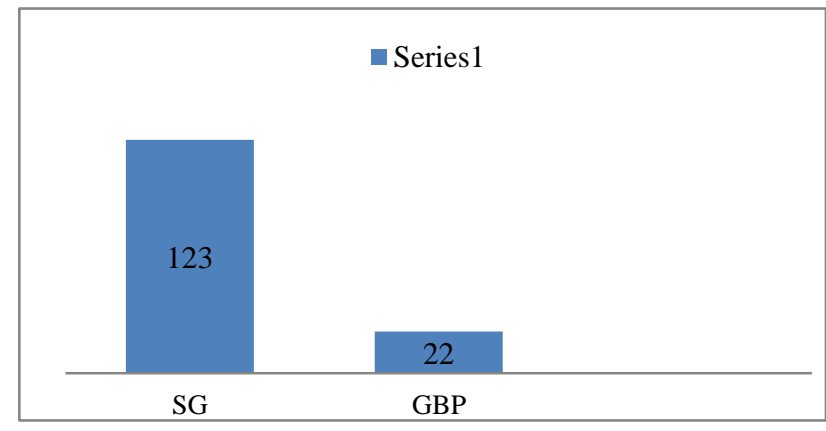

Figure 8: Type of surgery.

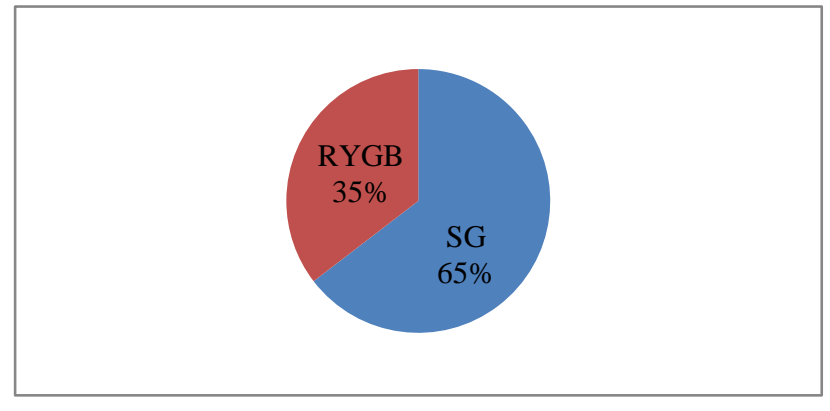

Figure 9: Type of surgery in DM. 
Table 4: Weight reduction.

\begin{tabular}{|llllll|}
\hline $\begin{array}{l}\text { Weight } \\
\text { in kg }\end{array}$ & $\begin{array}{l}\text { Pre op } \\
\text { weight }\end{array}$ & $\begin{array}{l}\text { Post } \\
\text { op } \\
\text { weight }\end{array}$ & $\begin{array}{l}\text { P value } \\
\text { (weight } \\
\text { control) }\end{array}$ & $\begin{array}{l}\text { Sq } \\
\text { value }\end{array}$ \\
\hline $\begin{array}{l}101- \\
120\end{array}$ & 28 & 138 & 0.000 & 1 & 170 \\
\hline$>120$ & 58 & 5 & 0.000 & 1 & 57 \\
\hline
\end{tabular}

Table 5: BMI reduction.

\begin{tabular}{|llllll|}
\hline BMI & $\begin{array}{l}\text { Pre } \\
\text { op } \\
\text { BMI }\end{array}$ & $\begin{array}{l}\text { Post } \\
\text { op } \\
\text { BMI }\end{array}$ & $\begin{array}{l}\text { P } \\
\text { value }\end{array}$ & $\begin{array}{l}\text { DOF } \\
\text { (reduction } \\
\text { in BMI) }\end{array}$ & $\begin{array}{l}\text { Chi } \\
\text { sq } \\
\text { value }\end{array}$ \\
\hline$<35$ & 3 & 124 & 0.000 & 1 & 205 \\
\hline $36-40$ & 50 & 14 & 0.000 & 1 & 26 \\
\hline $41-45$ & 40 & 4 & 0.000 & 1 & 34.7 \\
\hline$>45$ & 52 & 3 & 0.000 & 1 & 53.9 \\
\hline
\end{tabular}

\section{CONCLUSION}

Thus I conclude bariatric surgery LSG/LRYGBP is a definite choice for patient of Morbid obesity in gaining significant \& sustained weight reduction with positive shift noted in study equally by both the procedures $\&$ in morbid Obesity with T2DM. resolution of diabetes with normal or near normal glycemic control was observed in both group with slight edge of RYGBP as compared to SG overall both procedure gave adequate control of the disease $\&$ adds to quality of life of patient in a positive way giving cosmetic $\&$ therapeutic benefits.

Funding: No funding sources Conflict of interest: None declared

Ethical approval: The study was approved by the institutional ethics committee

\section{REFERENCES}

1. Pereira JA, Claro BM, Pareja JC, Chaim EA, Astiarraga BD, Saad MJA et al. Restored insulin inhibition on insulin secretion in nondiabetic severely obese patients after weight loss induced by bariatric surgery. International Journal of Obesity. 2003;27:219-26.

2. Velasquez-Mieyer PA, Cowan PA, Arheart KL, Buffington CK, Spencer KA, Connelly BE, et al. Suppression of insulin secretion is associated with weight loss and altered macronutrient intake and preference in a subset of obese adults. International Journal of Obesity. 2006;30:1104-10.

3. Karlsson J, Taft C, Rydén A, Sjöström L, Sullivan M. Ten-year trends in health-related quality of life after surgical and conventional treatment for severe obesity: the SOS intervention study. International Journal of Obesity. 2009;33:S33-40.

4. Cummings DE. Endocrine mechanisms mediating remission of diabetes after gastric bypass surgery
Anti-diabetic mechanisms of gastric bypass. International Journal of Obesity. 2009;33:S28-32.

5. Tadross JA, le Roux CW. The mechanisms of weight loss after bariatric surgery. 2009;35(6):5648.

6. Renard E. Bariatric surgery in patients with latestage type 2 diabetes: expected beneficial effects on risk ratio and outcomes. Can J Surg. 2009;52(6):E249-58.

7. Christou N, Efthimiou E. Five-year outcomes of laparoscopic adjustable gastric banding and laparoscopic Roux-en-Y gastric bypass in a comprehensive bariatric surgery program in Canada. 2009;52(6):E249-58.

8. Kashyap SR, Gatmaitan P, Brethauer S, Schauer P. Bariatric surgery for type 2 diabetes: Weighing the impact for obese patients. Diabetes Technol Ther. 2010;12(8):671-7.

9. Nandagopal R, Brown RJ, Rother KI. Resolution of Type 2 Diabetes Following Bariatric Surgery: Implications for Adults and Adolescents. Nat Rev Endocrinol. 2010;6(2):102-9.

10. Rubino F, R'bibo SL, del Genio F, Mazumdar M, McGraw TE. Metabolic surgery: the role of the gastrointestinal tract in diabetes mellitus. Surg Obes Relat Dis. 2012;8(5):641-7.

11. Ceppa EP, Ceppa DP, Omotosho PA, Dickerson JA, Park CW, Portenier DD. Algorithm to diagnose etiology of hypoglycemia after Roux-en-Y gastric bypass for morbid obesity: case series and review of the literature. J Diabetes Sci Technol. 2011;5(5):1263-82.

12. Ionut V, Bergman RN. Mechanisms responsible for excess weight loss after bariatric surgery. International Journal of Obesity. 2012;36:348-55.

13. Laurenius A, Larsson I, Bueter M, Melanson KJ, Bosaeus I, Forslund $\mathrm{BH}$, et al. Changes in eating behaviour and meal pattern following Roux-en-Y gastric bypass. Int J Obes. 2012;36(3):348-55.

14. Toghaw P, Matone A, Lenbury Y, De Gaetano A. Bariatric surgery and T2DM improvement mechanisms: a mathematical model. Theor Biol Med Model. 2012;9:16.

15. Dirksen C, Jørgensen NB, Bojsen-Møller KN, Kielgast U, Jacobsen SH, Clausen TR, et al. Gut hormones, early dumping and resting energy expenditure in patients with good and poor weight loss response after Roux-en-Y gastric bypass. Ann Surg. 2013;257(1):87-94.

16. Yip S, Plank LD, Murphy R. Gastric bypass and sleeve gastrectomy for type 2 diabetes: a systematic review and meta-analysis of outcomes. Curr Atheroscler Rep. 2013;15(11):366.

17. Via MA, Mechanick JI. The role of bariatric surgery in the treatment of type 2 diabetes: current evidence and clinical guidelines. J Hepatol. Curr Atheroscler Rep. 2013;15(11):366.

18. Immonen H, Hannukainen JC, Iozzo P, Soinio M, Salminen P, Lepomäki V, et al. Effect of bariatric surgery on liver glucose metabolism in morbidly 
obese diabetic and non-diabetic patients. J Hepatol. 2014;60(2):377-83.

19. Catheline JM, Fysekidis M, Bachner I, Bihan H, Kassem A, Dbouk R, et al. Five-year results of sleeve gastrectomy. J Visc Surg. 2013;150(5):30712.

20. Nannipieri M, Baldi S, Mari A, Colligiani D, Guarino D, Camastra S, et al. Roux-en-Y gastric bypass and sleeve gastrectomy: mechanisms of diabetes remission and role of gut hormones. Metab Syndr Relat Disord. J Clin Endocrinol Metab. 2013;98(11):4391-9.

21. Nestvold TK, Nielsen EW, Lappegård KT. Bariatric surgery reduces risk factors for development of type
2 diabetes mellitus in morbidly obese, nondiabetic patients. Curr Pharm Des. Metab Syndr Relat Disord. 2013;11(6):441-6.

22. Kalyvas AV, Vlachos K, Abu-Amara M, Sampalis JS, Glantzounis G. Bariatric surgery as metabolic surgery for diabetic patients. Obes Surg. 2013;23(3):292-9.

Cite this article as: Sharma R, Kela M, Khare Y, Mishra A, Bhandari M. Comparative analysis of LSG versus LRYGBP bariatric surgery in management of morbid obesity and type 2 diabetes mellitus in terms of percentage weight loss and T2DM resolution. Int Surg J 2015;2:641-6. 